\title{
Assimilação metabólica de nitrogênio em plântulas de seringueira cultivadas com nitrato ou amônio
}

\author{
Andrea Yu Kwan Villar Shan ${ }^{(1)}$, Luiz Edson Mota de Oliveira(2), Lisandro Tomas da Silva Bonome(3) \\ e Alessandro Carlos Mesquita(4)
}

\begin{abstract}
(1)Universidade Federal de Sergipe, Marechal Rondon, s/no, Jardim Rosa Elze, CEP 49100-000 São Cristóvão, SE. E-mail: ashan@ufs.br (2)Universidade Federal de Lavras, Campus Universitário, Caixa Postal 3.037, CEP 37200-000 Lavras, MG. E-mail: ledson@dbi.ufla.br (3)Universidade Federal da Fronteira Sul, Campus de Laranjeiras do Sul, Avenida Oscar Silva Guedes, no 1, Vila Alberti, CEP $85303-775$ Laranjeiras do Sul, PR. E-mail: lisandro.bonome@uffs.edu.br (4)Universidade do Estado da Bahia, Departamento de Tecnologia e Ciências Sociais, Campus III, Juazeiro, Caixa Postal 171, Avenida Dr. Edgard Chastinet Guimarães, s/no, São Geraldo, CEP 48905-680 Juazeiro, BA. E-mail: amesquita@uneb.br
\end{abstract}

Resumo - O objetivo deste trabalho foi avaliar a assimilação metabólica de nitrogênio em plântulas de seringueira cultivadas na presença de nitrato ou de amônio, por meio da quantificação da atividade das enzimas redutase do nitrato (RN), glutamina sintetase (GS), glutamato sintase (GOGAT) e glutamato desidrogenase (GDH). Os seguintes tratamentos foram avaliados: fontes de $\mathrm{N}$ - controle, sem aplicação de $\mathrm{N}$; amônio a 8 mmol L-1; e nitrato a $8 \mathrm{mmol} \mathrm{L}^{-1}$ - e tempos de exposição - 0 e 27 dias -, em arranjo fatorial 3x2, no delineamento inteiramente casualizado, com quatro repetições. A forma amoniacal promoveu maior assimilação metabólica de $\mathrm{N}$, o que resultou em maior acúmulo de aminoácidos. A assimilação, tanto da forma nítrica quanto da amoniacal, aconteceu principalmente via GS/GOGAT; parte do N nítrico é assimilado nas raízes, com pequena participação da GDH, e parte é translocada para outros órgãos. O N amoniacal é totalmente assimilado nas raízes, com significativa participação da GDH. Nas folhas, a GS participa tanto da assimilação primária como da reassimilação do amônio fotorrespirado, independentemente da fonte nitrogenada, enquanto a enzima GDH tem papel secundário, independentemente da fonte ou do tempo de exposição. A atividade da RN in vitro é detectada somente em raízes e caules.

Termos para indexação: Hevea brasiliensis, amônio, atividade enzimática, fonte de nitrogênio, metabolismo, nitrato.

\section{Metabolic assimilation of nitrogen in rubber tree seedlings grown with nitrate or ammonium}

\begin{abstract}
The objective of this work was to evaluate metabolic assimilation of nitrogen in rubber tree seedlings grown with nitrate or ammonium, by quantifying the activity of the enzymes nitrogen reductase (NR), glutamine synthetase (GS), glutamate synthase (GOGAT), and glutamate dehydrogenase (GDH). The following treatments were evaluated: nitrogen sources - control, without $\mathrm{N}$ application; $8 \mathrm{mmol} \mathrm{L}{ }^{-1}$ ammonium; and $8 \mathrm{mmol} \mathrm{L}^{-1}$ nitrate -, and exposure times - 0 and 27 days -, in a $3 \times 2$ factorial arrangement, in a completely randomized block design with four replicates. The ammoniacal form favored higher $\mathrm{N}$ metabolic assimilation, which lead to a higher aminoacid accumulation. Both nitrate and ammonium assimilations occurred mainly by GS/GOGAT route; part of the nitric nitrogen is assimilated in the roots, with little GDH participation, and the other part is translocated to other organs. Ammonium nitrogen is totally assimilated in roots, with a significant participation of GDH. In the leaves, GS participates in the primary assimilation, as well as in the photorespiratory ammonium re-assimilation, irrespective of the $\mathrm{N}$ source, while GDH has a secondary role, independently of the source or of the exposure time. In vitro RN activity is detected only in the roots and stems.
\end{abstract}

Index terms: Hevea brasiliensis, ammonium, enzyme activity, nitrogen source, metabolism, nitrate.

\section{Introdução}

A cultura da seringueira [Hevea brasiliensis (Willd. ex A. Juss.) Müll. Arg.] é explorada mundialmente por ser fonte natural de borracha, trazendo benefícios socioeconômicos, como geração de empregos e renda, e ambientais. Além disso, representa uma alternativa à utilização de fontes não renováveis na fabricação da borracha sintética, como o petróleo (Cornish, 2001). No entanto, a heveicultura ainda depende do desenvolvimento de tecnologias de cultivo e de exploração que sejam apropriadas às condições

Pesq. agropec. bras., Brasília, v.47, n.6, p.754-762, jun. 2012 
edafoclimáticas das diferentes regiões de cultivo. Assim, é importante o conhecimento de aspectos fisiológicos relacionados à assimilação de $\mathrm{N}$, por sua essencialidade como constituinte de importantes biomoléculas, por ser um nutriente cuja disponibilidade passa por grandes flutuações na rizosfera e por ser considerado um dos principais fatores limitantes para o crescimento e desenvolvimento das plantas (Miflin $\&$ Habash, 2002).

Os processos de absorção, assimilação e mobilização de $\mathrm{N}$ envolvem mecanismos para a máxima eficiência de utilização, que inclui um sistema complexo de vias metabólicas reguladas que se alternam em razão do armazenamento, da remobilização, da reassimilação, da reciclagem durante a fotorrespiração e da distribuição entre as vias primárias e secundárias do metabolismo (Stitt et al., 2002). Neste contexto, há uma forte dependência dos níveis de $\mathrm{N}$ endógeno e exógeno, da forma disponível e da energia disponibilizada, bem como da localização e da regulação das enzimas envolvidas, as quais determinam os órgãos ou sítios de assimilação.

No solo, a forma nitrogenada disponível para as plantas pode ser nítrica $\left(\mathrm{N}^{-\mathrm{NO}_{3}}{ }^{-}\right)$ou amoniacal $\left(\mathrm{N}-\mathrm{NH}_{4}{ }^{+}\right)$, e a primeira é mais abundante, em consequência do processo de nitrificação por bactérias que provocam a oxidação do amônio livre. No entanto, conforme as condições do solo, a forma amoniacal pode ser mais abundante pela inibição desses organismos. Nas plantas, o nitrato pode ser assimilado nas raízes, na parte aérea, ou em ambos o sítios, enquanto o amônio, por seus efeitos tóxicos, geralmente é assimilado nas raízes (Forde, 2002; Sodek, 2008).

A enzima redutase do nitrato $(\mathrm{RN})$, que catalisa a redução do nitrato a nitrito, é a principal porta de entrada de nitrogênio nítrico no metabolismo das plantas. O nitrito, por sua vez, é reduzido a amônio pela enzima redutase do nitrito ( $\mathrm{RNi}$ ), e este é assimilado pelas enzimas glutamina sintetase (GS) e glutamato 2-oxoglutarato aminotransferase (GOGAT), que formam o ciclo GS/GOGAT (Miflin \& Lea, 1976), ou ainda pela enzima glutamato desidrogenase (GDH), que participa de uma rota alternativa e realiza a catálise reversível da aminação do glutamato (Masclaux-Daubresse et al., 2006).

Várias pesquisas têm sido conduzidas para elucidar a contribuição quantitativa de cada enzima de assimilação durante o crescimento e o desenvolvimento das plantas
(Miflin \& Habash, 2002; Tcherkez \& Hodges, 2008); porém, a existência de múltiplas isoenzimas, distribuídas em diferentes compartimentos celulares e órgãos, tem gerado resultados divergentes, o que dificulta a compreensão dos processos assimilatórios (Ishiyama et al., 2004). Além disso, em condições fisiológicas particulares, vias metabólicas alternativas podem ser acionadas e operar conjuntamente ou não, para atender à demanda fisiológica vegetal (Tercé-Laforgue et al., 2004a; Masclaux-Daubresse et al., 2005).

Finalmente, ressalte-se que o $\mathrm{N}$ disponível no solo para as plantas assume as formas nítrica $\left(\mathrm{N}^{-\mathrm{NO}_{3}}{ }^{-}\right)$e amoniacal $\left(\mathrm{N}_{-} \mathrm{NH}_{4}{ }^{+}\right)$, e que diferentes espécies ou até mesmo genótipos de uma mesma espécie podem apresentar preferências por nitrato ou amônio, conforme as pressões seletivas e consequentes adaptações fisiológicas (Yoneyama et al., 2003; Allègre et al., 2004; Tercé-Laforgue et al., 2004b).

O objetivo deste trabalho foi avaliar a assimilação metabólica de $\mathrm{N}$ em plântulas de seringueira cultivadas na presença de nitrato ou de amônio, por meio da quantificação da atividade das enzimas redutase do nitrato (RN), glutamina sintetase (GS), glutamato sintase (GOGAT) e glutamato desidrogenase (GDH).

\section{Material e Métodos}

Sementes de seringueira, após seis meses de armazenamento, foram colocadas para germinar em casa de vegetação, em Lavras, $\mathrm{MG}\left(21^{\circ} 14^{\prime} \mathrm{S}, 45^{\circ} 00^{\prime} \mathrm{W}\right.$, altitude de $910 \mathrm{~m}$ ), com clima Cwa, segundo a classificação de Köppen.

Foram utilizadas bandejas de plástico, com areia lavada com água destilada e previamente analisada quanto à ausência de $\mathrm{N}$, pelo método de Kjeldahl (Cunniff, 1998). Vinte dias após a germinação, ao atingirem o estádio "palito", as plântulas foram selecionadas quanto à uniformidade da parte aérea e radicular e transplantadas, em número de três, para vasos de plástico de $3 \mathrm{~L}$, que continham areia lavada nas mesmas condições descritas anteriormente. As plantas foram irrigadas com água destilada por 60 dias, quando foram feitas as primeiras coletas para a realização das determinações no tempo 0 , tendo-se procedido, em seguida, aos tratamentos: solução nutritiva de Bolle-Jones modificada (Lemos et al., 1999), com N à concentração de $8 \mathrm{mmol} \mathrm{L}^{-1}$, na forma de amônio (T2) ou nitrato (T3); e sem adição de qualquer forma de nitrogênio (T1, plantas controle). 
Os tratamentos foram iniciados com a adição do mesmo volume de solução a cada vaso, cujo excesso foi retido nos pratos colocados sob eles. A cada 24 horas, o excesso foi retornado para os vasos, e o volume não retido pelo substrato foi completado com água destilada, de modo a uniformizar o volume para todos os vasos. A solução foi ajustada à $\mathrm{pH} 6,5$, quando necessário. As soluções foram renovadas a intervalos de sete dias. Foram realizadas, também, aplicações do fungicida Kumulus df (Basf) (enxofre a 80\% e ingredientes inertes a 20\%) quinzenalmente, para impedir a proliferação de fungos na parte aérea das plantas.

Aos 27 dias, foram feitas novas coletas. As plantas coletadas no tempo 0 e aos 27 dias de tratamento foram divididas em parte aérea (limbo foliar no estádio D), caulinar (regiões meristemáticas) e radicular (raízes de absorção). Uma parte do material foi submetida à secagem em estufa de circulação forçada de ar a $100^{\circ} \mathrm{C}$, até obtenção de massa constante, e utilizada para a determinação da concentração de $\mathrm{N}$ total; outra foi congelada em $\mathrm{N}$ líquido e armazenada em ultra-freezer a $-80^{\circ} \mathrm{C}$, até a realização das análises de aminoácidos e atividades enzimáticas. Os tratamentos foram realizados com a combinação entre três fontes de $\mathrm{N}$ e dois tempos de coleta, em arranjo 3x2, distribuídos em delineamento inteiramente casualizado, com quatro repetições. As médias obtidas foram comparadas pelo teste de Tukey, a 5\% de probabilidade.

A concentração de $\mathrm{N}$ total foi obtida a partir do material vegetal seco e moído (100 mg), conforme método de Kjeldahl (Cunniff, 1998). Para a determinação de aminoácidos livres, amostras dos tecidos foram homogeneizadas em etanol a $80 \%$, à proporção de $1: 10(\mathrm{p} / \mathrm{v})$ e submetidas a três extrações sucessivas, em banho termostatizado a $60^{\circ} \mathrm{C}$ por $30 \mathrm{~min}$. Após cada extração, foram centrifugadas a $10.000 \mathrm{~g}$, por $10 \mathrm{~min}$, e os extratos etanólicos foram reunidos e submetidos à secagem a vácuo a $45^{\circ} \mathrm{C}$. Os resíduos obtidos foram ressuspendidos em $3 \mathrm{~mL}$ de água destilada e constituíram o extrato bruto, utilizado para a determinação de aminoácidos livres, conforme método de Yemm \& Cocking (1955).

Para a realização dos ensaios da redutase do nitrato (RN), NADH-glutamato sintase (NADH-GOGAT) e glutamato desidrogenase (GDH), o extrato enzimático foi obtido por meio da homogeneização dos tecidos, em tampão fosfato $0,1 \mathrm{~mol} \mathrm{~L}^{-1} \mathrm{pH} 7,5$, DTT $2 \mathrm{mmol} \mathrm{L}^{-1}$,
PMSF 1 mmol L-1 e EDTA $5 \mathrm{mmol} \mathrm{L}^{-1}$. Em seguida, o extrato foi centrifugado a $16.000 \mathrm{~g}$ por $20 \mathrm{~min}$, e o sobrenadante foi utilizado como fonte enzimática. Para a realização do ensaio da glutamina sintetase (GS), o extrato foi obtido por meio da homogeneização dos tecidos, em tampão fosfato $0,1 \mathrm{~mol} \mathrm{~L}^{-1} \mathrm{pH} \mathrm{7,0,} \mathrm{DTT}$ $2 \mathrm{mmol} \mathrm{L}-1$, PMSF $1 \mathrm{mmol} \mathrm{L}^{-1}$, EDTA $3 \mathrm{mmol} \mathrm{L}^{-1}$ e $\mathrm{MgCl}_{2}$ 0,01 mol L-1. Em seguida o extrato foi centrifugado a $16.000 \mathrm{~g}$ por $10 \mathrm{~min}$ e o sobrenadante foi utilizado como fonte enzimática. Em todas as extrações, utilizou-se a proporção de $1: 4(\mathrm{p} / \mathrm{v})$ para raízes e 1:5 (p/v) para caules e folhas, exceto para os extratos obtidos para GS, em que foi utilizada a proporção de 1:3(p/v) para raízes, $1: 4(\mathrm{p} / \mathrm{v})$ para caules e $1: 5(\mathrm{p} / \mathrm{v})$ para folhas.

$\mathrm{A}$ atividade da $\mathrm{RN}$ foi determinada pela adição de alíquotas do extrato (100-200 $\mu \mathrm{L}^{-1}$, conforme tecido) ao meio de reação, constituído por tampão fosfato $0,1 \mathrm{~mol}$ $\mathrm{L}^{-1} \mathrm{pH} 7,5, \beta$-NADH $0,2 \mathrm{mmol} \mathrm{L}^{-1}$ e $\mathrm{KNO}_{3} 10 \mathrm{mmol} \mathrm{L}^{-1}$, com volume final de $2 \mathrm{~mL}$. A reação foi iniciada pela adição de $\mathrm{NADH}$, após a incubação do meio por $3 \mathrm{~min}$ a $30^{\circ} \mathrm{C}$. A oxidação do NADH foi monitorada pelo decréscimo da absorbância em $340 \mathrm{~nm}$, durante $10 \mathrm{~min}$, a intervalos de $1 \mathrm{~min}$, tendo-se iniciado a quantificação a partir dos 5 min de decaimento. A atividade total da enzima foi expressa em $\mu \mathrm{mol}$ de NADH por minuto por grama de matéria fresca $\left(\mu \mathrm{mol} \mathrm{min}^{-1} \mathrm{~g}^{-1}\right)$.

A atividade da GS foi determinada pela adição de alíquotas do extrato (200-500 $\mu \mathrm{L}^{-1}$, conforme tecido) ao meio de reação, constituído de tampão Tris- $\mathrm{HCl}$ $0,1 \mathrm{~mol} \mathrm{~L}^{-1} \mathrm{pH} \mathrm{7,5, \beta -mercaptoetanol} 0,01 \mathrm{~mol} \mathrm{~L}^{-1}$, $\mathrm{MgSO}_{4} \cdot 7 \mathrm{H}_{2} \mathrm{O}$ 0,02 mol L-1 $\mathrm{NH}_{2} \mathrm{OH} . \mathrm{HC1}$ 0,01 mol L-1, glutamato monossódico $0,05 \mathrm{~mol} \mathrm{~L}^{-1}$ eATP $0,01 \mathrm{~mol} \mathrm{~L}^{-1}$, com volume final de $1 \mathrm{~mL}$. Amistura foi incubada a $30^{\circ} \mathrm{C}$ durante $30 \mathrm{~min}$, e a reação foi paralisada pela adição de $1 \mathrm{~mL}$ de uma solução que continha $0,37 \mathrm{~mol} \mathrm{~L}^{-1}$ de $\mathrm{FeCl}_{3}, 0,67 \mathrm{~mol} \mathrm{~L}^{-1}$ de $\mathrm{HCl}$ e $0,2 \mathrm{~mol} \mathrm{~L}^{-1}$ de TCA. Em seguida, a solução foi centrifugada a $16.000 \mathrm{~g}$ por 5 min, e a concentração do produto enzimático foi determinada a $540 \mathrm{~nm}$ contra um padrão de glutamil hidroxamato (GHA). A atividade total da enzima foi expressa em mmol GHA $\min ^{-1} \mathrm{~g}^{-1}$.

A atividade da NADH-GOGAT foi determinada com a adição de alíquotas do extrato (100-200 $\mu \mathrm{L}^{-1}$, conforme tecido) ao meio de reação composto de tampão

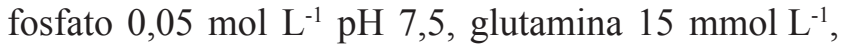
2- $\alpha$-cetoglutarato $15 \mathrm{mmol} \mathrm{L}^{-1}, \mathrm{KCl} 0,01 \mathrm{~mol} \mathrm{~L}^{-1}$, $\beta$-mercaptoetanol 0,02 $\mathrm{mol} \mathrm{L}^{-1}$ e $\beta$-NADH 0,2 mmol L-1, 
com um volume final de $2 \mathrm{~mL}$. A reação foi iniciada pela adição de NADH, após a incubação do meio por 3 min a $30^{\circ} \mathrm{C}$. A oxidação do NADH foi monitorada pelo decréscimo da absorbância em $340 \mathrm{~nm}$, durante $10 \mathrm{~min}$ em intervalos de $1 \mathrm{~min}$. A atividade total da enzima foi expressa em mmol GLU $\mathrm{min}^{-1} \mathrm{~g}^{-1}$.

A atividade da GDH foi determinada com a adição dos alíquotas do extrato (50-200 $\mu^{-1}$, conforme tecido) ao meio de reação, composto de tampão Tris-HCl 0,1 mol L-1 $\mathrm{pH} 7,8,\left(\mathrm{NH}_{4}\right)_{2} \mathrm{SO}_{4} 0,1 \mathrm{~mol} \mathrm{~L}^{-1}$, 2- $\alpha$-cetoglutarato $0,01 \mathrm{~mol} \mathrm{~L}^{-1}$ e $\mathrm{CaCl}_{2} 4 \mathrm{mmol} \mathrm{L}^{-1}$, com um volume final de $2 \mathrm{~mL}$. A reação foi iniciada pela adição de NADH, após a incubação do meio por 3 min a $30^{\circ} \mathrm{C}$. A oxidação do NADH foi monitorada pelo decréscimo da absorbância em $340 \mathrm{~nm}$, durante $10 \mathrm{~min}$ em intervalos de $1 \mathrm{~min}$. A atividade total da enzima foi expressa em mmol GLU $\mathrm{min}^{-1} \mathrm{~g}^{-1}$.

\section{Resultados e Discussão}

As plantas cultivadas na presença de amônio apresentaram maior assimilação metabólica de $\mathrm{N}$ aos 27 dias após o tratamento (DAT) (Figura 1). Cruz et al. (2006) obtiveram a mesma resposta com mandioca. A origem da seringueira, natural da região amazônica - onde cerca de $70 \%$ dos solos são ácidos -, poderia justificar esta preferência, pois, nesses ambientes, a existência da forma amoniacal é favorecida.

Do total de $\mathrm{N}$ amoniacal fornecido às plantas, $4 \%$ foi absorvido e convertido em $\mathrm{N}$ orgânico. Nas plantas que receberam nitrato, esse valor foi de 3\%. Embora a absorção da forma amoniacal seja energeticamente mais econômica para a planta, por seu estado reduzido, altos níveis nos tecidos podem gerar toxidez (Britto \& Kronzucker, 2002). Portanto, quando ocorre absorção excessiva de amônio, esse baixo custo energético não é vantajoso, pois os processos de detoxificação também consomem energia (Von Wiren \& Merrick, 2004). As plantas apresentaram bom crescimento vegetativo, sem nenhum sintoma de toxidez. Lemos et al. (1999) observaram que plantas de seringueira com amônio como única fonte de $\mathrm{N}$ apresentam maior crescimento em altura e diâmetro, em comparação àquelas que recebem nitrato.

A maior parte do $\mathrm{N}$ incorporado foi alocada nas folhas, independentemente das fontes avaliadas, o que está de acordo com Delú-Filho et al. (1998). Nas raízes, assim como nas folhas, verificou-se aumento na concentração de $\mathrm{N}$ com o tempo, independentemente da fonte. Contudo, nos caules, a absorção de $\mathrm{N}$ não foi influenciada pelo tempo. Neste caso, as plantas cultivadas com amônio mostraram maior concentração de $\mathrm{N}\left(0,62,0,68\right.$ e $0,85 \mathrm{mmol} \mathrm{N} \mathrm{g}^{-1}$ MS para sem tratamento, com nitrato e com amônio, respectivamente), independentemente do tempo de exposição.

Aos 27 DAT observaram-se as maiores concentrações de aminoácidos em raízes e caules, independentemente da fonte de N (Figura 1). Entretanto, a observação de que a concentração de $\mathrm{N}$ total radicular não variou com as fontes, enquanto a concentração de aminoácidos livres foi significativamente maior nas plantas cultivadas com amônio, indica que o amônio absorvido foi completamente assimilado nas raízes, e que parte da concentração de nitrato absorvida foi transportada para outros órgãos de armazenamento ou assimilação. A maior concentração de aminoácidos livres nos caules das plantas que receberam amônio confirma que o amônio é prontamente assimilado, o que conduz à maior síntese de aminoácidos na raiz e maior concentração de aminoácidos livres translocados no xilema.

Nas folhas das plantas cultivadas com amônio, a concentração de aminoácidos livres não se alterou com o tempo, o que indica que, provavelmente, os aminoácidos que chegam a esses tecidos são rapidamente utilizados. No entanto, para as plantas cultivadas na presença de nitrato, houve aumento na concentração de aminoácidos livres, que poderiam ter resultado do nitrato translocado e assimilado nos tecidos foliares.

A atividade in vitro da $\mathrm{RN}$ presente nas raízes aumentou nas plantas cultivadas com nitrato (Figura 2), o que era esperado e evidencia a indução da enzima pelo substrato (Lea et al., 2006), já que nas plantas cultivadas na presença de amônio e na ausência de $\mathrm{N}$ a atividade reduziu.

A atividade enzimática observada nos meristemas caulinares das plantas cultivadas com nitrato, nesse mesmo período, evidencia que parte do nitrato absorvido pelas raízes foi translocada para outros locais de armazenamento e ou assimilação, o que é confirmado, também, pelo aumento na concentração de aminoácidos (Figura 1). Cazetta \& Villela (2004) encontraram atividade enzimática caulinar em Urochloa arrecta, com valores três vezes menores do 
que aqueles encontrados nas folhas, o principal sítio de redução nessa espécie.

As plantas cultivadas na presença de amônio ou na ausência de $\mathrm{N}$ mostraram o mesmo comportamento, com redução da atividade enzimática da $\mathrm{RN}$ nas raízes e aumento nos caules. Vale ressaltar que, em ambas, a atividade dessa enzima pode ser decorrente da assimilação do nitrato pré-existente, mobilizado
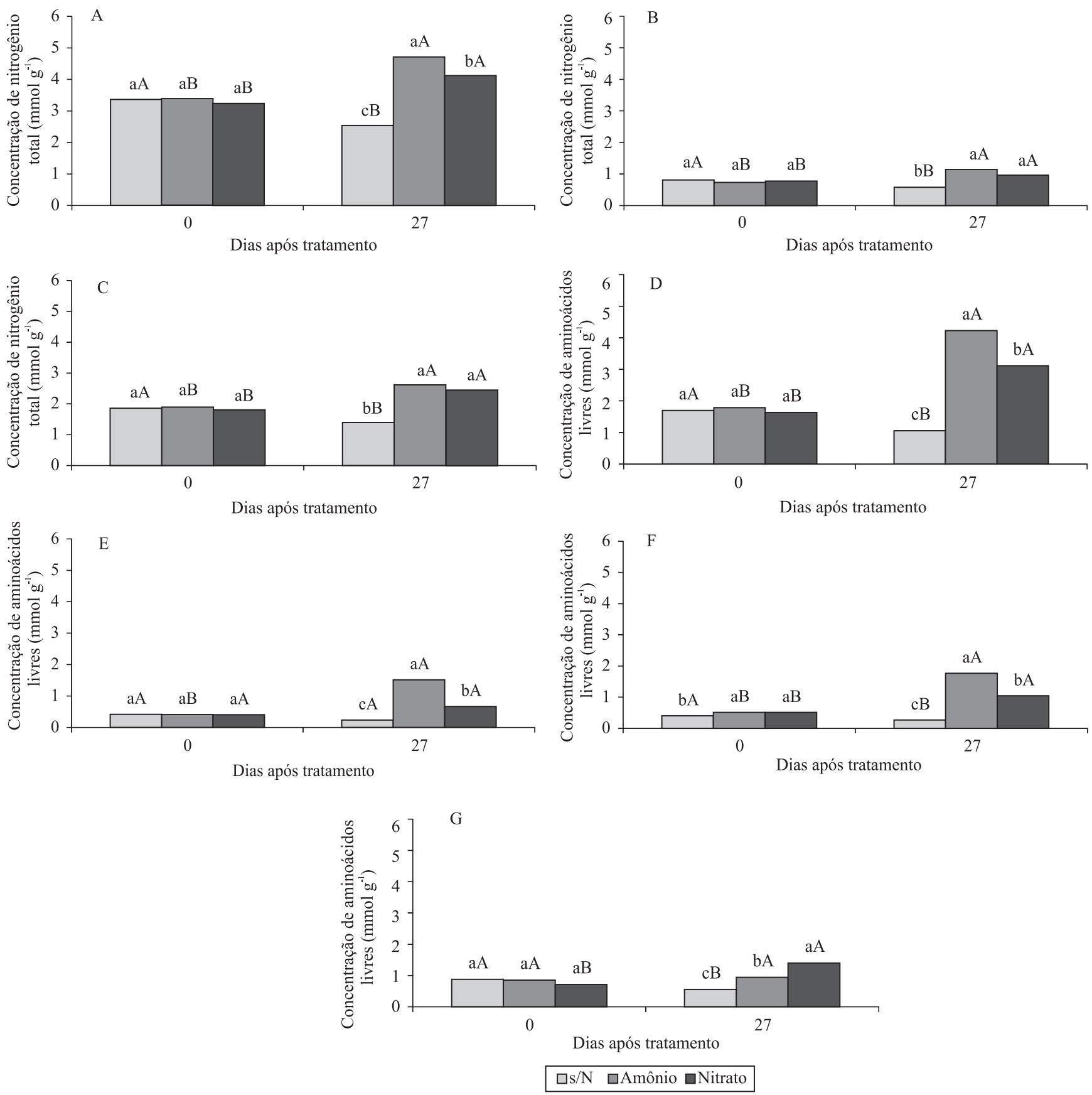

Figura 1. Concentração de nitrogênio total na planta (A), raízes (B) e folhas (C), e de aminoácidos livres na planta (D), raízes $\left(\right.$ E), caules $(\mathrm{F})$ e folhas $(\mathrm{G})$ de plântulas de seringueira, cultivadas na ausência de $\mathrm{N}(\mathrm{s} / \mathrm{N})$ e na presença de amônio $\left(\mathrm{N}-\mathrm{NH}_{4}{ }^{+}\right)$ ou nitrato $\left({\mathrm{N}-\mathrm{NO}_{3}}^{-}\right)$, de acordo com o tempo de exposição aos tratamentos ( 0 e 27 dias). Letras minúsculas comparam fontes de nitrogênio no tempo, e letras maiúsculas comparam tempos dentro de fontes de nitrogênio, pelo teste de Tukey, a $5 \%$ de probabilidade. 
pelos processos germinativos. Donato et al. (2004) avaliaram a atividade enzimática em variedades de cana-de-açúcar cultivadas com diferentes níveis de $\mathrm{N}$, e observaram que, para todas as variedades cultivadas com amônio e na ausência de $\mathrm{N}$, a atividade da $\mathrm{RN}$ esteve associada à presença da isoforma constitutiva, $\mathrm{O}$ que também pode ser o caso da seringueira.

Com relação aos tecidos foliares, a hipótese de que a assimilação metabólica do nitrato em seringueira acontece somente no sistema radicular (Delú-Filho et al., 1998) tem sido contestada, em razão da observação do transporte de nitrato no xilema (Alves,
2001). No entanto, os trabalhos que buscaram avaliar a atividade in vivo não obtiveram respostas conclusivas, assim como no presente trabalho, em que se utilizou o método in vitro. Porém, observou-se aumento na concentração de aminoácidos nas folhas das plantas cultivadas com nitrato (Figura 1), que poderia vir dos processos de alocação, já que a enzima ativa foi detectada somente nos tecidos de raiz e nos tecidos meristemáticos do caule. Entretanto, fisiologicamente, a assimilação do nitrato é energeticamente dispendiosa, e a alta produção de açúcares de poder redutor e a energia advinda dos processos fotossintéticos mostram
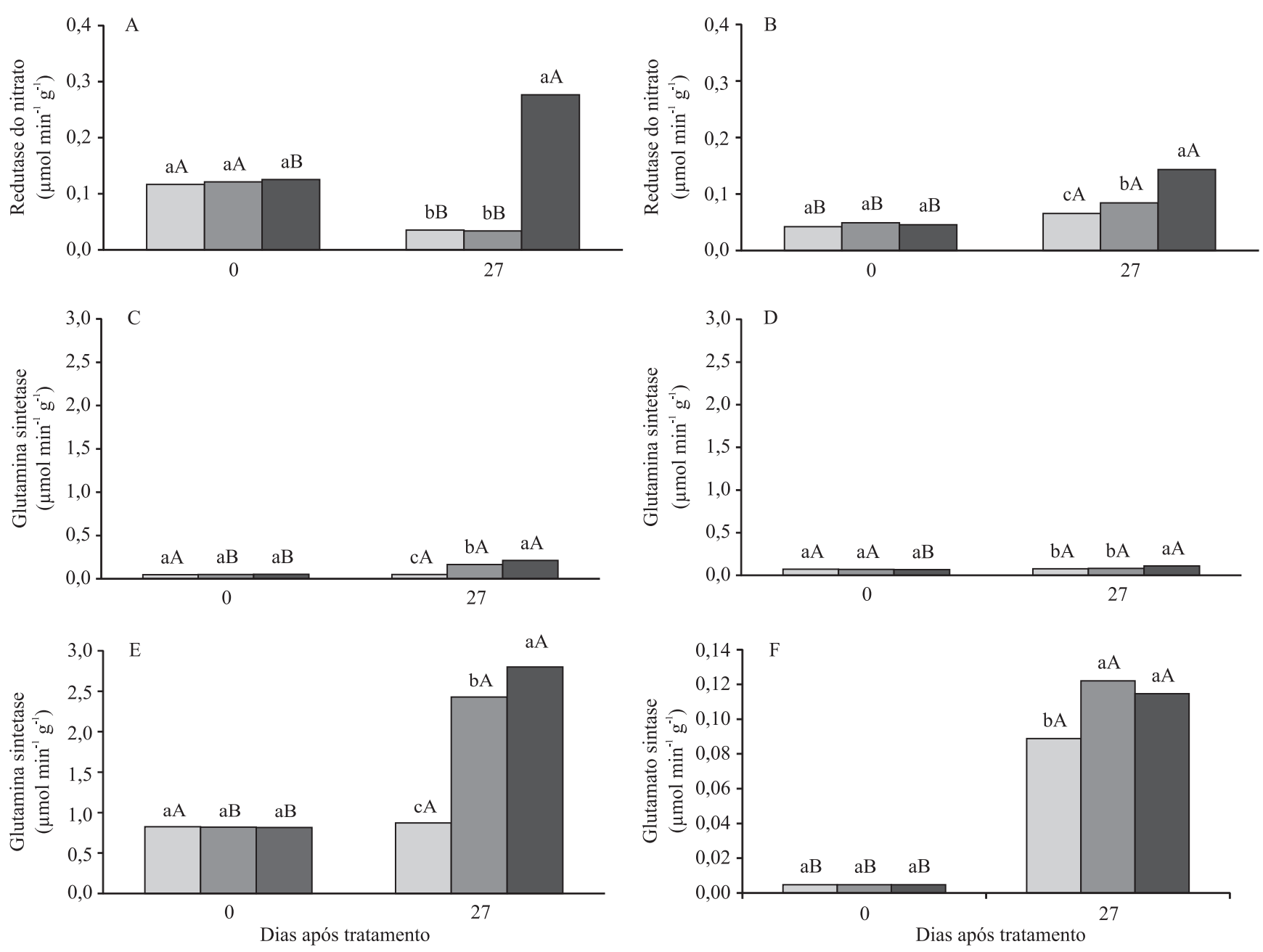

$\square \mathrm{s} / \mathrm{N} \quad \square$ Amônio $\square$ Nitrato

Figura 2. Atividade da redutase do nitrato nas raízes (A) e caules (B), glutamina sintetase nas raízes (C), caules (D) e folhas (E), e glutamato sintase nas raízes (F) de plântulas de seringueira, cultivadas na ausência de $\mathrm{N}(\mathrm{s} / \mathrm{N})$ e na presença de amônio $\left(\mathrm{N}_{-} \mathrm{NH}_{4}{ }^{+}\right)$ou nitrato $\left(\mathrm{N}_{-} \mathrm{NO}_{3}{ }^{-}\right)$, de acordo com o tempo de exposição aos tratamentos $(0$ e 27 dias). Letras minúsculas comparam fontes de nitrogênio no tempo, e letras maiúsculas comparam tempos dentro de fonte de nitrogênio, pelo teste de Tukey, a $5 \%$ de probabilidade. 
que seria mais vantajoso assimilar o nitrato nas folhas (Glass et al., 2002). Além disso, o transporte de nitrato pelo floema ainda é controverso (Taiz \& Zeiger, 2009). Assim, a inexistência da enzima ativa nas folhas pode ser decorrente da insensibilidade dos métodos de avaliação adotados.

A atividade da GS foi mais pronunciada nas folhas do que nas raízes e caules (Figura 2), e provavelmente esteve associada à assimilação primária e secundária de N (Masclaux-Daubresse et al., 2006). O teste de comparação de médias mostrou que, nas raízes, houve aumento da atividade enzimática em plantas cultivadas na presença de amônio ou nitrato. Esse aumento foi maior em plantas cultivadas com nitrato, o que evidencia que a presença de amônio ou nitrato no meio de cultivo induziu ao aumento da catálise enzimática.

A atividade da $\mathrm{RN}$ nas raízes, associada aos valores observados para GS nos mesmos tecidos, evidencia que a participação da GS é assimilar tanto o amônio absorvido quanto o oriundo da redução do nitrato, como pode ser visto pelo aumento na concentração de aminoácidos (Figura 1). Nos caules, somente as plantas cultivadas na presença de nitrato sofreram um leve aumento na atividade de RN. Miflin \& Habash (2002) relataram que, para a manutenção do balanço de $\mathrm{C}$ e N, a GS pode ser localizada em tecidos e órgãos envolvidos com a geração e o transporte de $\mathrm{N}$ reduzido. Nas folhas, a atividade da GS, aos 27 DAT, aumentou em plantas cultivadas com amônio ou nitrato, e a maior atividade ocorreu nas plantas cultivadas com nitrato. Nesse período, o aumento significativo em aminoácidos das plantas cultivadas com nitrato indica que a GS foliar estaria sintetizando aminoácidos a partir do amônio produzido pela assimilação do nitrato in situ e, nesse caso, mais uma vez, levanta-se a mencionada hipótese de insensibilidade dos métodos de detecção.

QuantoaocomportamentodaenzimaNADH-GOGAT (Figura 2), aos 27 DAT as raízes apresentaram, para todos os tratamentos, aumento na atividade enzimática, com valores semelhantes entre as plantas cultivadas na presença de amônio ou nitrato, maiores que os valores para o tratamento sem nitrogênio. Nos caules, observouse que a atividade dessa enzima foi independentemente da fonte nitrogenada, tendo respondido apenas ao tempo

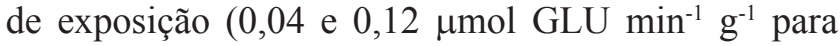
tempos 0 e 27 dias, respectivamente). A comparação das atividades enzimáticas obtidas para GS com as obtidas para NADH-GOGAT mostra que a transaminação é inferior à síntese de glutamina, o que indica que a glutamina sintetizada pode ser translocada para os tecidos foliares para a transaminação. A atividade da Fd-GOGAT não foi avaliada no presente trabalho; porém, trabalhos anteriores mostraram alta atividade dessa enzima, o que indica sua participação tanto na assimilação primária do $\mathrm{N}$ quanto na assimilação secundária (fotorrespiração) (Lemos et al., 1999).

Observou-se aumento na atividade da GDH radicular em todos os tratamentos (Figura 3), com maior valor médio nas plantas cultivadas na presença de amônio, o que confirma que essa enzima é estimulada pelo amônio e indica que a catálise, nessas condições de suprimento de N, ocorre no anabolismo de aminoácidos. Segundo Lancien et al. (2000), a reação de aminação é favorecida por amônio, glutamina ou açúcares.

Nas raízes de plantas cultivadas na ausência de $\mathrm{N}$, observou-se aos 27 DAT que os valores de GDH foram quatro vezes maiores do que os observados para
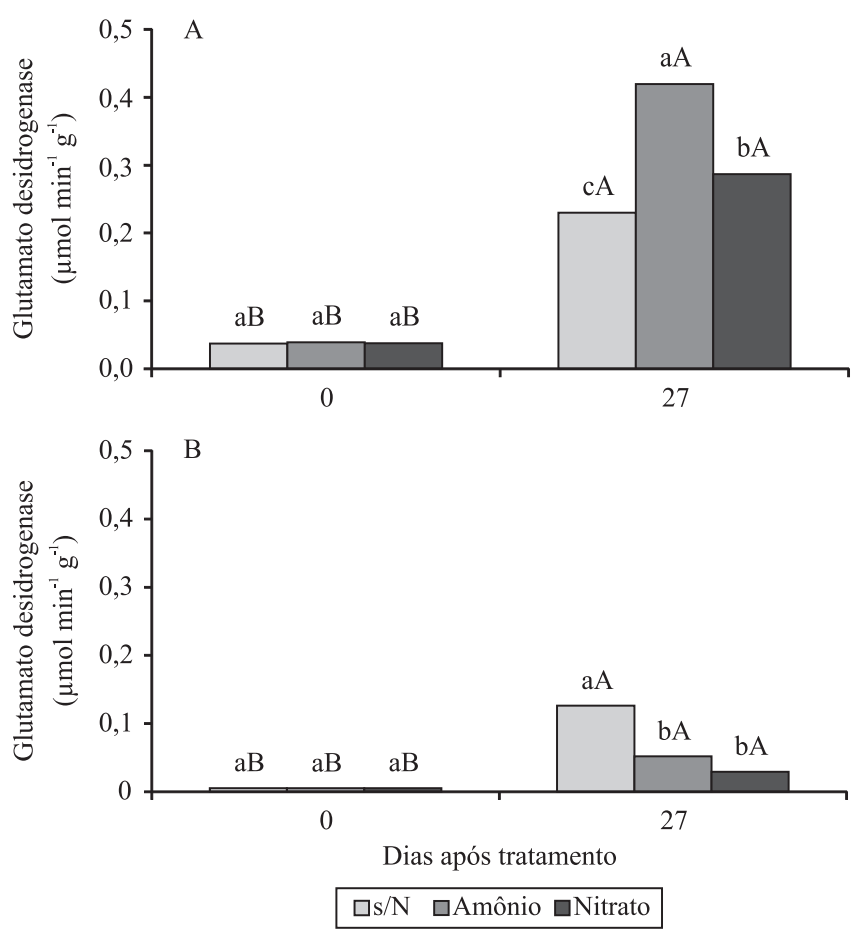

Figura 3. Atividade da glutamato desidrogenase nas raízes (A) e caules (B) de plântulas de seringueira, cultivadas na ausência de $\mathrm{N}(\mathrm{s} / \mathrm{N})$ e na presença de amônio $\left(\mathrm{N}-\mathrm{NH}_{4}^{+}\right)$ou nitrato $\left(\mathrm{N}-\mathrm{NO}_{3}{ }^{-}\right)$, de acordo com o tempo de exposição aos tratamentos ( 0 e 27 dias). Letras minúsculas comparam fontes de nitrogênio no tempo, e letras maiúsculas comparam tempos dentro de fonte de nitrogênio, pelo teste de Tukey, a $5 \%$ de probabilidade. 
GS (Figura 2) e, em razão da condição de deficiência do mineral e das reduções dos níveis de $\mathrm{N}$ total e aminoácidos (Figura 1), supõe-se que a GDH atue com função catabólica. Melo-Oliveira et al. (1996) mostraram que a função catabólica da isoenzima era reabastecer o ciclo dos ácidos tricarboxílicos, ao prover 2-oxoglutarato em condições de limitação de carbono. No entanto, Aubert et al. (2001), ao utilizar técnicas de ressonância magnética nuclear $\left(\mathrm{RMN}^{13} \mathrm{C} \mathrm{e}\right.$ $\left.{ }^{31} \mathrm{P}\right)$, mostraram que a participação da GDH se estende tanto para atender à demanda do metabolismo de $\mathrm{C}$, provendo 2-oxoglutarato quando o pool de metabólitos como malato é reduzido, quanto à demanda de substrato, para que a via primária de assimilação possa ocorrer.

Nos caules, observou-se aumento da atividade enzimática aos 27 DAT, em todos os tratamentos, sem diferenças entre as plantas cultivadas na presença de amônio ou nitrato, que apresentaram valores menores do que as plantas cultivadas na ausência do nutriente. Nas folhas não houve interação entre os tempos de exposição e as fontes; portanto, pode-se inferir que a enzima esteve presente ativamente em todos os tempos e em todos os tratamentos. Embora no presente trabalho não se tenha avaliado a enzima Fd-GOGAT, e sabendo-se que o ciclo GS/GOGAT é o maior responsável pelo mecanismo de assimilação de amônio primário e secundário em plantas superiores (Persson et al., 2006), verificou-se que a enzima GDH parece atuar conjuntamente com a GS. No entanto, sua real função na utilização de diferentes formas de $\mathrm{N}$ só pode ser determinada por métodos radioativos de detecção, pois, segundo Oaks (1995), os ensaios in vitro não discriminam o sentido da reação.

\section{Conclusões}

1. Plântulas de seringueira apresentam melhor nutrição quanto a nitrogênio total e aminoácidos, quando se utiliza amônio como fonte de nitrogênio.

2. A assimilação metabólica, tanto da forma nítrica quanto da amoniacal, acontece preferencialmente via GS/GOGAT, com forte dependência entre a atividade da GS e o pool de nitrato celular, bem como entre a atividade da GDH e o pool de amônio celular.

3. Parte do nitrogênio nítrico é assimilado nas raízes, com pequena participação da GDH; outra parte é translocada para caules e folhas, enquanto o nitrogênio amoniacal é assimilado totalmente nas raízes, com significativa participação da GDH.

4. A GS foliar participa efetivamente da assimilação primária e secundária do amônio, independentemente da fonte nitrogenada, enquanto a GDH foliar é ativa, em papel secundário, independentemente das fontes ou do tempo de exposição aos tratamentos.

5. A RN, pelo método in vitro aplicado, é detectada somente nas raízes e caules.

\section{Agradecimentos}

À Coordenação de Aperfeiçoamento de Pessoal de Nível Superior, pelo apoio financeiro; ao Comitê Orientador, pelas contribuições científicas.

\section{Referências}

ALLÈGRE, A.; SILVESTRE, J.; MORARD, P.; KALLERHOFF, J.; PINELLI, E. Nitrate reductase regulation in tomato roots by exogenous nitrate: a possible role in tolerance to long-term root anoxia. Journal of Experimental Botany, v.55, p.2625-2634, 2004.

ALVES, E.M. Redução do nitrato, assimilação do amônio e transporte do nitrogênio em plantas jovens de seringueira. 2001. 57p. Dissertação (Mestrado) - Universidade Federal de Lavras, Lavras.

AUBERT, S.; BLIGNY, R.; DOUCE, R.; GOUT, E.; RATCLIFFE, R.G.; ROBERTS, J.K.M. Contribution of glutamate dehydrogenase to mitochondrial glutamate metabolism studied by ${ }^{13} \mathrm{C}$ and ${ }^{31} \mathrm{P}$ nuclear magnetic resonance. Journal of Experimental Botany, v.52, p.37-45, 2001.

BRITTO, D.T.; KRONZUCKER, H.J. $\mathrm{NH}_{4}{ }^{+}$toxicity in higher plants: a critical review. Journal of Plant Physiology, v.159, p.567-584, 2002.

CAZETTA, J.O.; VILLELA, L.C.V. Nitrate reductase in leaves and steams of tanner grass (Brachiaria radicans Napper). Scientia Agricola, v.61, p.640-648, 2004.

CORNISH, K. Similarities and differences in rubber biochemistry among plant species. Phytochemistry, v.57, p.1123-1134, 2001.

CRUZ, J.L.; PELACANI, C.R.; ARAÚJO, W.L. Efeito do nitrato e amônio sobre o crescimento e eficiência de utilização do nitrogênio em mandioca. Bragantia, v.65, p.467-475, 2006.

CUNNIFF, P. (Ed.). Official methods of analysis of AOAC International. $16^{\text {th }}$ ed. Gaithersburg: AOAC International, 1998.

DELÚ-FILHO, N.; OLIVEIRA, L.E.M. de; ALVES, J.D.; PURCINO, A.A.C. Redução de nitrato e assimilação de amônio em plantas jovens de Hevea brasiliensis cultivadas sob níveis crescentes de nitrato. Revista Brasileira de Fisiologia Vegetal, v.10, p.185-190, 1998.

DONATO, V.M.T.S.; ANDRADE, A.G. de; SOUZA, E.S. de; FRANÇA, J.G.E. de; MACIEL, G.A. Atividade enzimática em 
variedades de cana-de-açúcar cultivadas in vitro sob diferentes níveis de nitrogênio. Pesquisa Agropecuária Brasileira, v.39, p.1087-1093, 2004.

FORDE, B.G. Local and long-range signaling pathways regulating plant responses to nitrate. Annual Review of Plant Biology, v.53, p.203-224, 2002.

GLASS, A.D.M.; BRITTO, D.T.; KAISER, B.N.; KINGHORN, J.R.; KRONZUCKER, H.J.; KUMAR, A.; OKAMOTO, M.; RAWAT, S.; SIDDIQI, M.Y.; UNCLES, S.E.; VIDMAR, J.J. The regulation of nitrate and ammonium transport systems in plants. Journal of Experimental Botany, v.53, p.855-864, 2002.

ISHIYAMA, K.; INOUE, E.; WATANABE-TAKAHASHI, A.; OBARA, M.; YAMAYA, T.; TAKAHASHI, H. Kinetic properties and ammonium-dependent regulation of cytosolic isoenzymes of glutamine synthetase in Arabidopsis. Journal of Biological Chemistry, v.279, p.16598-16605, 2004.

LANCIEN, M.; GADAL, P.; HODGES, M. Enzyme redundancy and the importance of 2-oxoglutarate in higher plant ammonium assimilation. Plant Physiology, v.123, p.817-824, 2000.

LEA, U.S.; LEYDECKER, M.-T.; QUILLERÉ, I.; MEYER, C.; LILLO, C. Posttranslational regulation of nitrate reductase strongly affects the levels of free amino acids and nitrate, whereas transcriptional regulation has only minor influence. Plant Physiology, v.140, p.1085-1094, 2006.

LEMOS, G.B. de; DELÚ-FILHO, N.; OLIVEIRA, L.E.M. de; PURCINO, A.A.C. Atividade das enzimas de assimilação do nitrogênio em plantas jovens de seringueira cultivadas com diferentes relações de nitrato e amônio. Revista Brasileira de Fisiologia Vegetal, v.11, p.113-118, 1999.

MASCLAUX-DAUBRESSE, C.; CARRAYOL, E.; VALADIER, M.H. The two nitrogen mobilization- and senescence-associated GS1 and GDH genes are controlled by $\mathrm{C}$ and $\mathrm{N}$ metabolites. Planta, v.221, p.580-588, 2005.

MASCLAUX-DAUBRESSE, C.; REISDORF-CREN, M.; PAGEAU, K.; LELANDAIS, M.; GRANDJEAN, O.; KRONENBERGER, J.; VALADIER, M.; FERAUD, M.; JOUGLET, T.; SUZUKI, A. Glutamine synthetase-glutamate synthase pathway and glutamate dehydrogenase play distinct roles in the sink-source nitrogen cycle in tobacco. Plant Physiology, v.140, p.444-456, 2006.

MELO-OLIVEIRA, R.; OLIVEIRA, I.C.; CORUZZI, G.M. Arabidopsis mutant analysis and gene regulation define a nonredundant role for glutamate dehydrogenase in nitrogen assimilation. Proceedings of the National Academy of Sciences of the United States of America, v.93, p.4718-4723, 1996.
MIFLIN, B.J.; HABASH, D.Z. The role of glutamine synthetase and glutamate dehydrogenase in nitrogen assimilation and possibilities for improvement in the nitrogen utilization of crops. Journal of Experimental Botany, v.53, p.979-987, 2002.

MIFLIN, B.J.; LEA, P.J. The pathway of nitrogen assimilation in plants. Phytochemistry, v.15, p.873-885, 1976.

OAKS, A. Evidence for deamination by glutamate dehydrogenase in higher plants: reply. Canadian Journal of Botany, v.73, p.1116-1117, 1995.

PERSSON, J.; GARDESTRÖM, P.; NASHOLM, T. Uptake, metabolism and distribution of organic and inorganic nitrogen sources by Pinus sylvestris. Journal of Experimental Botany, v.57, p.2651-2659, 2006.

SODEK, L. Metabolismo do nitrogênio. In: KERBAUY, G.B. Fisiologia vegetal. 2.ed. Rio de Janeiro: Guanabara Koogan, 2008. p.94-113.

STITT, M.; MULlER, C.; MATT, P.; GIBON, Y.; CARILLO, P.; MORCUENDE, R.; SCHEIBLE, W.R.; KRAPP, A. Steps towards an integrated view of nitrogen metabolism. Journal of Experimental Botany, v.53, p.959-970, 2002.

TAIZ, L.; ZEIGER, E. Fisiologia vegetal. 4.ed. Porto Alegre: Artmed, 2009. 820p.

TCHERKEZ, G.; HODGES, M. How stable isotopes may help to elucidate primary nitrogen metabolism and its interaction with (photo) respiration in $\mathrm{C}_{3}$ leaves. Journal of Experimental Botany, v.59, p.1685-1693, 2008.

TERCÉ-LAFORGUE, T.; DUBOIS, F.; FERRARIO-MÉRY, S.; POU DE CRECENZO, M.A.; SANGWAN, R.; HIREL, B. Glutamate dehydrogenase of tobacco is mainly induced in the cytosol of phloem companion cells when ammonia is provided either externally or released during photorespiration. Plant Physiology, v.136, p.4308-4317, 2004a.

TERCÉ-LAFORGUE, T.; MÄCK, G.; HIREL, B. New insights towards the function of glutamate dehydrogenase revealed during source-sink transition of tobacco (Nicotiana tabacum) plants grown under different nitrogen regimes. Physiologia Plantarum, v.120, p.220-228, 2004b.

VON WIREN, N.; MERRICK, M. Regulation and function of ammonium carriers in bacteria, fungi and plants. Topics in Current Genetics, v.9, p.95-120, 2004.

YEMM, E.W.; COCKING, E.C. The determination of amino acid with ninhydrin. Analyst, v.80, p.209-213, 1955.

YONEYAMA, T.; ITO, O.; ENGELLAR, W.M.G.H. Uptake, metabolism and distribution of nitrogen in crop plants traced by enriched and natural ${ }^{15} \mathrm{~N}$ : progress over the last 30 years. Phytochemistry Reviews, v.2, p.121-132, 2003.

Recebido em 27 de dezembro de 2011 e aprovado em 31 de maio de 2012

Pesq. agropec. bras., Brasília, v.47, n.6, p.754-762, jun. 2012 